\title{
Chapter 4 \\ The Concept of Hierarchical Structure of Large Marine Ecosystems in the Zoning of Russian Arctic Shelf Seas
}

\author{
Kirill M. Petrov and Andrey A. Bobkov
}

\begin{abstract}
Main features of biogeographical regionalization were developed in previous notes of authors. In this chapter a review on the new information on large marine ecosystems is given based on strong theoretical and empirical material including own research. The originality of method of a research consists that the description of the sea basin (ecoregion) the three-rank system of units considering zonal, vertical and azonal distinctions of the environment which influence the distribution of marine inhabitants is used. The principles of the regionalization of hierarchical structure are discussed on the example of the Barents Sea.
\end{abstract}

\subsection{Introduction}

The system of the Global Ocean bioregionalization developed by Spalding et al. (2007) includes 12 realms, 62 provinces and 232 ecoregions (large marine systems). In the Arctic realm whole marine basins (seas) are treated as ecoregions. Their biogeographical features are determined by the degree of their isolation, surface and deep water circulation system, river runoff, tides, thermohaline regime, waving condition of formation and dynamics of ice cover, bottom relief and geological features, ground deposits, types of shore and coast line configuration. The essential role in the formation of oceanographic regime of water area is coupling the interaction between the sea and atmosphere. As a solution to detailed biogeographical division of large marine ecosystems, a landscape and bionomic approach was suggested (Petrov 2004, 2012), where the patterns of marine organisms distribution are related

K.M. Petrov $(\bowtie) \bullet$ A.A. Bobkov

Institute of Earth Science, Saint-Petersburg State University, 33/35, 10th line, Vasilievsky Island, Saint-Petersburg 199178, Russia

e-mail: k.petrov@spbu.ru; abbk-437@yandex.ru 
to the conditions of their habitat. According to this approach sea bottom organisms which are usually called benthos are consistently found in the combination of relief and types of sea sediments with a specific set of hydrological and hydrochemical factors forming in the whole the large marine ecosystem consisting of local ecoregions. A detailed regionalization of such large marine ecosystems in range of sea basins is necessary for carrying out monitoring, rational use and protection of marine biological resources at different hierarchical levels. Experience of authors of present paper on biogeographical regionalization of the sea basins is based on rich theoretical and empirical material, including on own researches executed earlier summarized in works of Petrov (2009, 2012), Bobkov and Petrov (2013).

\subsection{Methodical Approach}

The biogeographical heterogeneity of the Global Ocean can be treated from landscape and bionomic positions. This approach is based on statement that the specificity of biotic composition is determined by natural conditions. The formation of a bionomic structure in a marine ecoregion is influenced by oceanographic processes which cover water masses, the bottom and boundary layers of the atmosphere (Petrov 2004, Spalding et al. 2007). The landscape-bionomic differentiation of large marine ecosystems reflects three directions of these processes: zonal (latitudinal), vertical (deep) and azonal (geomorphological). In a multicomponent scheme of interactions, two main functional links are distinguished: hydrological and geologogeomorphological (Petrov 2004). Water masses serve as the main ecological factor of biogeographical regionalization. Warm Atlantic waters are delivered into the Barents Sea by Norwegian, West Spitsbergen, Nordcape and West Greenland currents. Cold waters and ice are taken away from the Arctic with East Greenland and Labrador currents. The influence of a hydrological factor is manifested in zonal differentiation of the sea basins. The geological structure and bottom relief constitute a lithogenic basis on which underwater landscapes are formed. Relief and
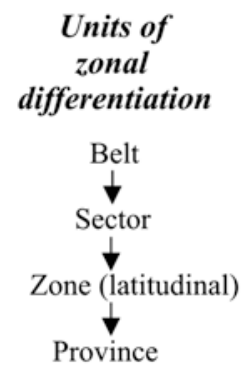

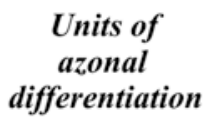

Marine bassin
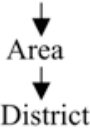

Units of vertical differentiation

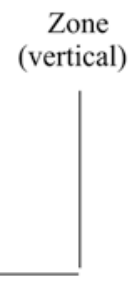

Fig. 4.1 Three-rank system of units of landscape-bionomic regionalization (Petrov 2004) 
types of ground define the geomorphological subdivision of the bottom which can be used as the basis for studying benthic organisms distributions. The geologogeomorphological structure of the sea floor serves as a framework for defining a system of azonal units regionalization which are not connected with system of zonal units. The both above mentioned feedback loops bear certain environmental pressure affecting to third connection - the bionomic one. Thus, a three-rank system of units at regional level was earlier proposed by Petrov (2004) the essence of which is given in Fig. 4.1. It can be seen that the underwater landscape connects all three units of differentiation. It is characterized by a common geological structure, relief and homogeneous hydroclimate with a corresponding set of bottom organisms and is accepted as an initial unit in hierarchical structure of marine ecoregion.

\subsection{Units of Zonal Differentiation}

The Arctic Ocean and its seas belong to the Arctic geographical belt subdivided into Polar and Arctic nature zones. In the Arctic zone change of environmental conditions occurs in both latitudinal and longitudinal (sectors) directions. Four climatic sectors may be distinguished in the North Polar area: Atlantic, Siberian, Canadian and Pacific (Korotkevich 1985). The Barents Sea belongs to the Atlantic coastal sector.

The division of the Barents Sea Arctic zone into arctic and subarctic provinces is determined by the influence of warm and cold currents forming a stable water mass transfer with characteristic zonal groups of plankton and benthos (Figs. 4.2 and 4.3).

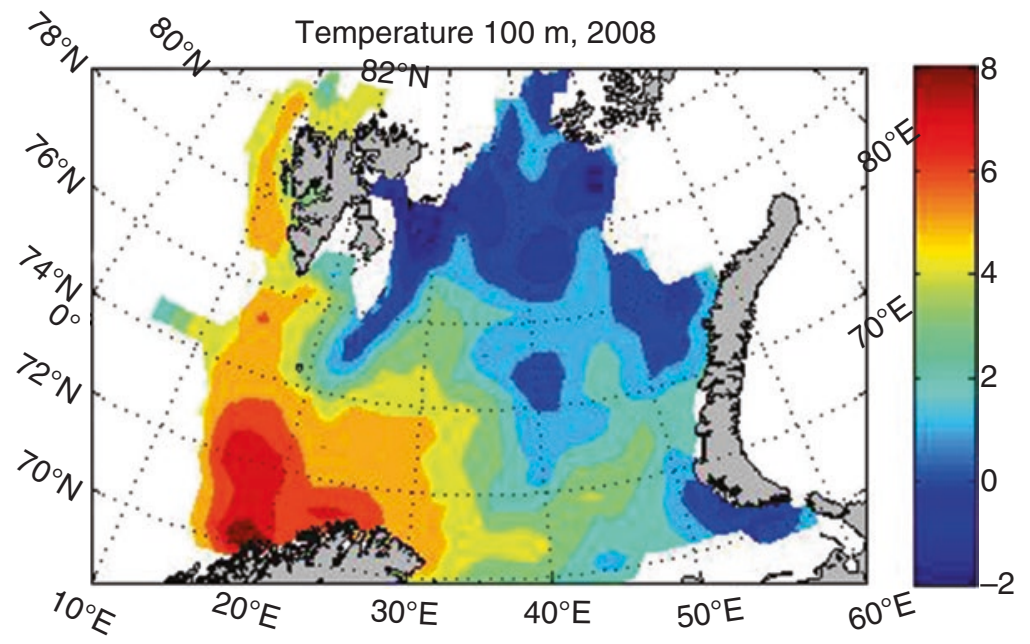

Fig. 4.2 Average water temperature distribution at $100 \mathrm{~m}$ depth in summer of 2008 illustrating spreading of warm and cold waters (Skern-Mauritzen and Fall 2010). Yellow-brown color of spectrum corresponds to the boreal zone, turquoise-green - to the subarctic province, and blue - to the arctic province of arctic zone 


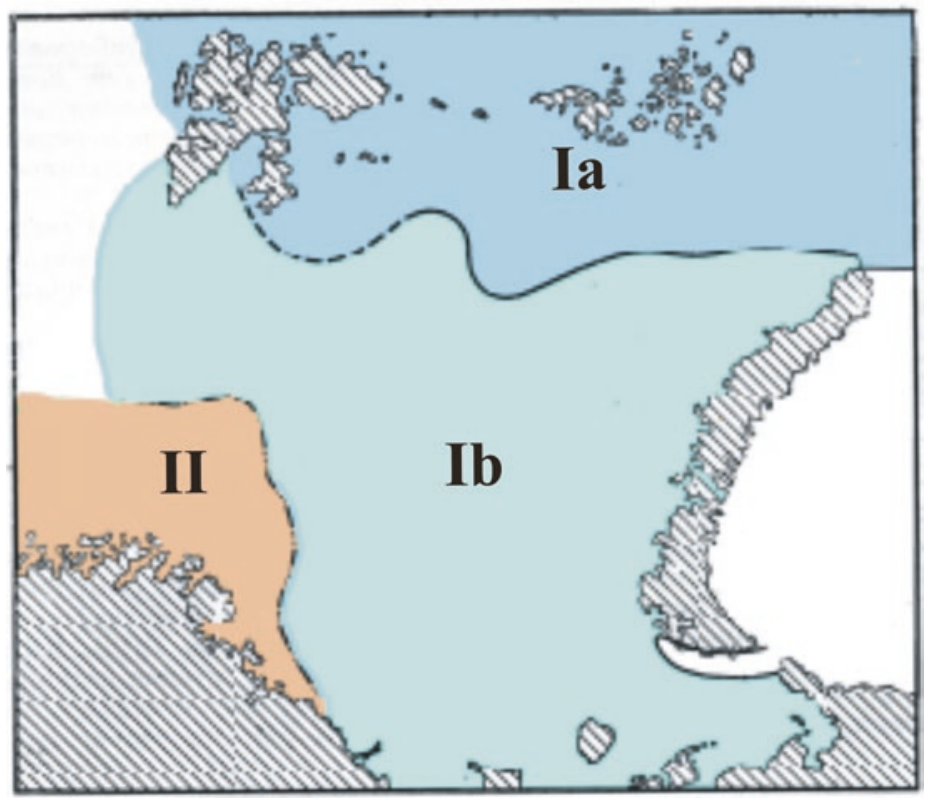

Fig. 4.3 Zonal differentiation of the Barents Sea: $I$ arctic zone: $I a$ arctic province, $I b$ subarctic province, II boreal zone, extrazonal Barents Sea province (Modified from Zenkevitch 1963)

The central part of the basin is situated in the subarctic province. The south-western part of the sea is the most warm area heated by Atlantic waters and belongs to boreal zone. The Barents Sea extrazonal province (Petrov 2009). Located at the intersection of warm and cold waters, the Barents Sea contains a biota which constantly experiences changes with either the onset of warm-water forms or their replacement with cold-water forms. Therefore, the zonal boundaries are vague and encapsulate the arctic and boreal zones through narrow dynamic transitions.

\subsection{Units of Vertical Differentiation}

The vertical differentiation reflects the change of environmental conditions with depth. The properties of vertical zones depend on the natural zone (province) in which they are formed: boreal, subarctic or arctic. The main units of the vertical differentiation are littoral, sublittoral and elitoral zones which are subdivided into floors and stages. An example from the East Murman (the Kola Peninsula) is given. The littoral zone (with the tide amplitude of about $3 \mathrm{~m}$ ) is divided into two floors. An indicator of the first floor is the belt of Fucus vesiculesus; the second one seen in syzygy tides is characterized by a Laminaria digitata. The sublittoral zone is divided into three floors. Its components are shown in Fig. 4.4. The upper floor consists of two stages. In the first $(I$ a $)$ the community of Laminaria digitata 


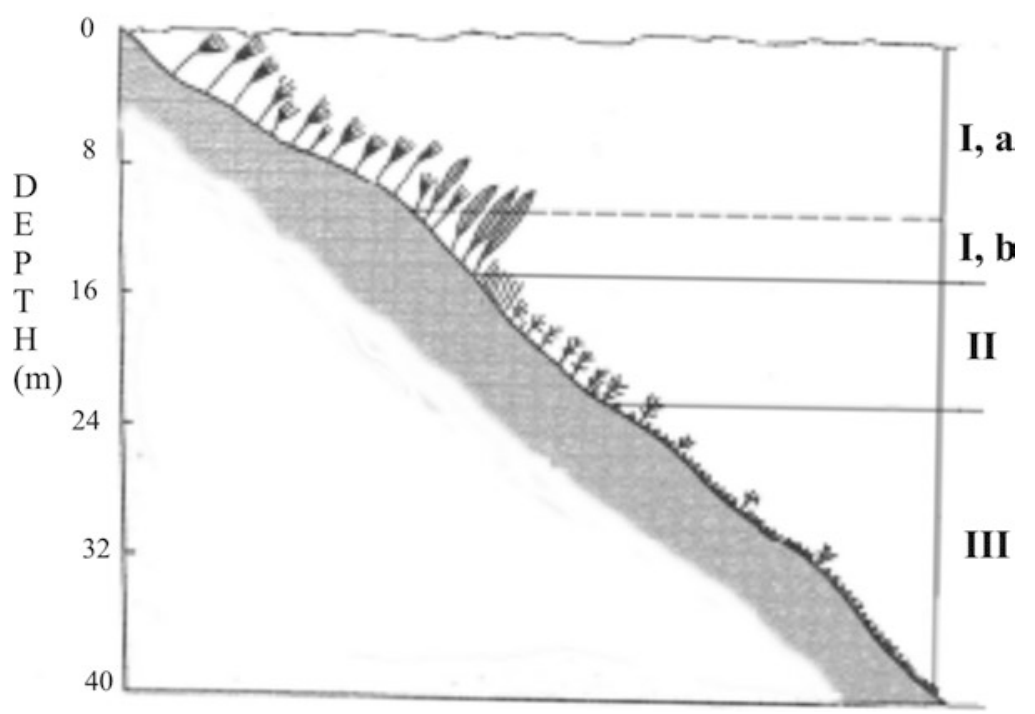

Fig. 4.4 Vertical differentiation of sublittoral zone of the underwater coastal slope of East Murman: I-III - sublittoral floors: I upper floor, Ia upper stage (community of Laminaria digitata), Ib lower stage (community of Alaria esculenta), II middle floor (community of Chorda tomentosa + Odonthalia dentata), III ground floor (community of Balanus balanus) (Modified from Propp 1971)

prevails. In the second $(I b)$ - community of Alaria esculenta. In the middle floor (II) the community of Chorda tomentosa + Odonthalia dentata dominates; in the ground floor - community of Balanus balanus (Propp 1971). The upper (surface) stage is located on the border between the atmosphere and sea surface, it is subject to the seasonal fluctuations depending mainly on the budget of solar radiation. On the bottom of the Barents Sea the thermal regime is defined distribution of arctic, subarctic and boreal water masses. In underwater landscapes, where the temperature near the sea floor is below freezing all year round, high arctic fauna dominates. A diver moving from the littoral to the sublittoral zone will find changes in fauna distribution from boreal to high arctic one, even in the same area that confirms its dependence on the water temperature.

\subsection{Units of Azonal Differentiation}

The azonal features of marine basin are presented to us as following: the size, depth and bottom hollow form, a relief of the shore and degree of isolation from the Global Ocean. In general, the distribution of life forms on the seabed is controlled by properties of geological structure, bottom relief and sea sediments and these items gives a reason to distinguish a system of azonal units shown in Fig. 4.1, namely: the marine basin, area, district, region (landscape). 


\subsection{Discussion}

Landscape-bionomic concept characteristic of the Barents Sea as of the large marine system marked in scheme of ecoregions of Spalding et al. (2007) shown in Fig. 4.5 under \# 18 was elaborated. Its structural elements became reason to discuss. The concept is based on the WWWF's Arctic Programme (Barents Sea .... 2003) visualized on a map in Fig. 4.6. The map was taken as a basis issue where ecoregions shown in Fig. 4.6, are correlated with features deriving from joint analysis of distributions of principal geomorphological elements and macrobenthos shown in Figs. 4.7 and 4.8 respectively. A brief description of these ecoregions is provided below.

1. Southwestern ecoregion in Fig. 4.6 (1 a, Norway near-shore areas, and 1b, the Kola Peninsula near-shore areas) corresponds to Southwestern geomorphological area in Fig. 4.7. The coastline with narrow shelf is washed by waters of the North Atlantic current. The boreal fauna with relic forms in deep fjords prevails. Owing to the influence of warm Atlantic water, coastal sites have the greatest variety of benthos presented with brown and red algae, sessile and vagile sestonophagous - filtrators on a stony slope. The variety and productivity of benthos decreases with depth.

2. Ecoregion of the Pechora Sea in Fig. 4.6 corresponds to Kanin-Pechora flat geomorphological area in Fig. 4.7. In shallow waters on sandy-mud grounds sessile and vagile organisms prevail: sestonophagous, detritivores and ground feeders inhabiting the seabed. The dominating communities are bivalve molluscs Ciliatocardium ciliatum, Macoma calcarea and Serripes groenlandicus.

3. Ecoregion of the Central basin south from the polar front in Fig. 4.6 corresponds to the southern part of the Central Barents rift in and the West Barents Sea tectonic and geomorphological areas in Fig. 4.7 and represents a wide transition zone between the Atlantic and Arctic waters. Deep-water communities of ground

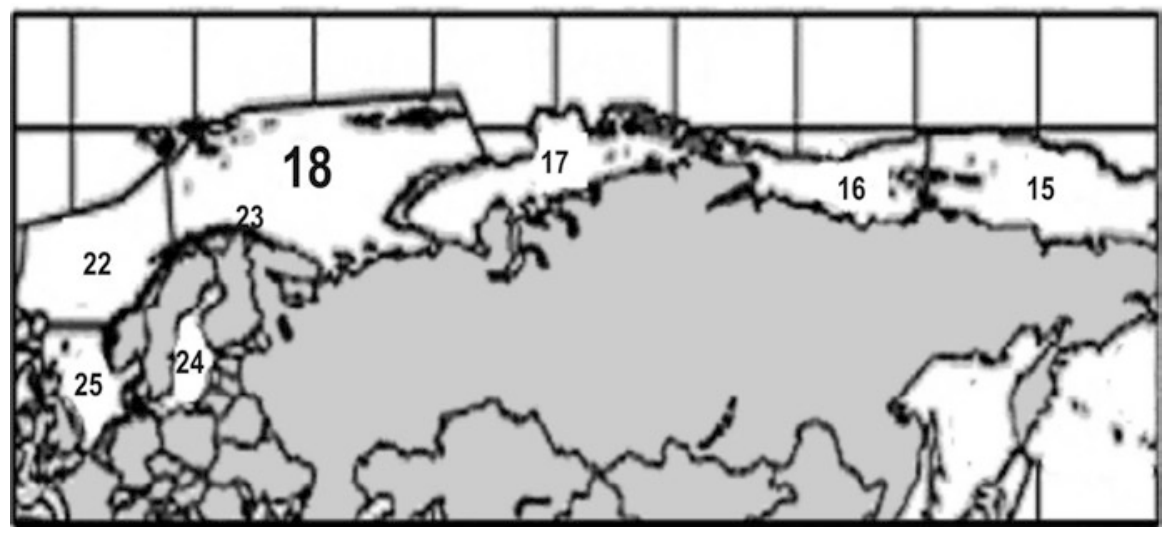

Fig. 4.5 Ecoregions of Euro-Asian shelf of Arctic realm modified from Spalding et al. (2007). Fragment. 18 - North and East Barents Sea ecoregion 


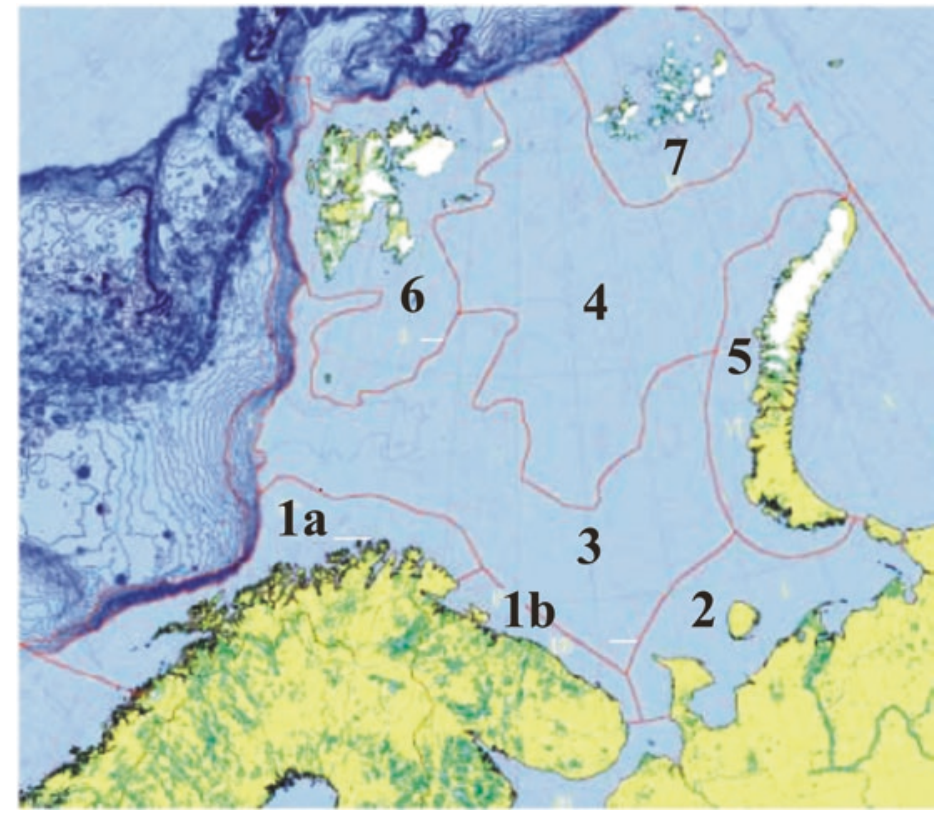

Fig. 4.6 Ecoregions of the Barents Sea: - South-Western ( $1 a$ near-shore areas of Norway, and $1 b$ the Kola Peninsula near-shore areas), 2 Pechora Sea, 3 Central basin south from the polar front, 4 Central basin north from the polar front, 5 Novaya Zemlya shore, 6 Svalbard Archipelago and banks of Spitsbergen, 7 Franz Josef Land Archipelago (Modified from Barents Sea Ecoregion 2003)

feeders polychaeta and sipunculida (Golfingia sp., Spiochaetopterus typicus, Ctenodiscus crispatus) as well as the community of holothurian (Trochostoma sp.) are characteristic. The Eastern part of this ecoregion coincides with the Central Lowland geomorphological area inhabited by boreal-arctic and arctic fauna of detritivores. Community of bivalve molluscs can be observed of family Astartidae (Elliptica elliptica and Astarte crenata), and deep-water community of polychaeta, sipunculida and holothurian can be found.

4. Ecoregion of the Central basin north from the polar front in Fig. 4.6 is situated in sphere of spreading of Arctic water masses. It occupies the northern part of the Central Barents Sea rift and belongs to the North Barents Sea geomorphological area in Fig. 4.7. This is a zone of detritivores collecting detritus from a seabed. The deep-water community includes Ophiopleura borealis and foraminifer Hormosina globulifera, and also the community of bivalve molluscs of family Astartidae (Elliptica elliptica and Astarte crenata).

5. Ecoregion of the Novaya Zemlya shore in Fig. 4.6 corresponds to the Novaya Zemlya tectonic and geomorphological areas in Fig. 4.7. It is washed by the Arctic water mass with some influence of Atlantic water in the west. On sandymud bottom grounds the trophic groups comprise sessile and vagile sestonophagous-filtrators Hyatella arctica, Strongylocentrotus sp., whereas Ophiura robusta, Balanus balanus are dominating in bentic community. 


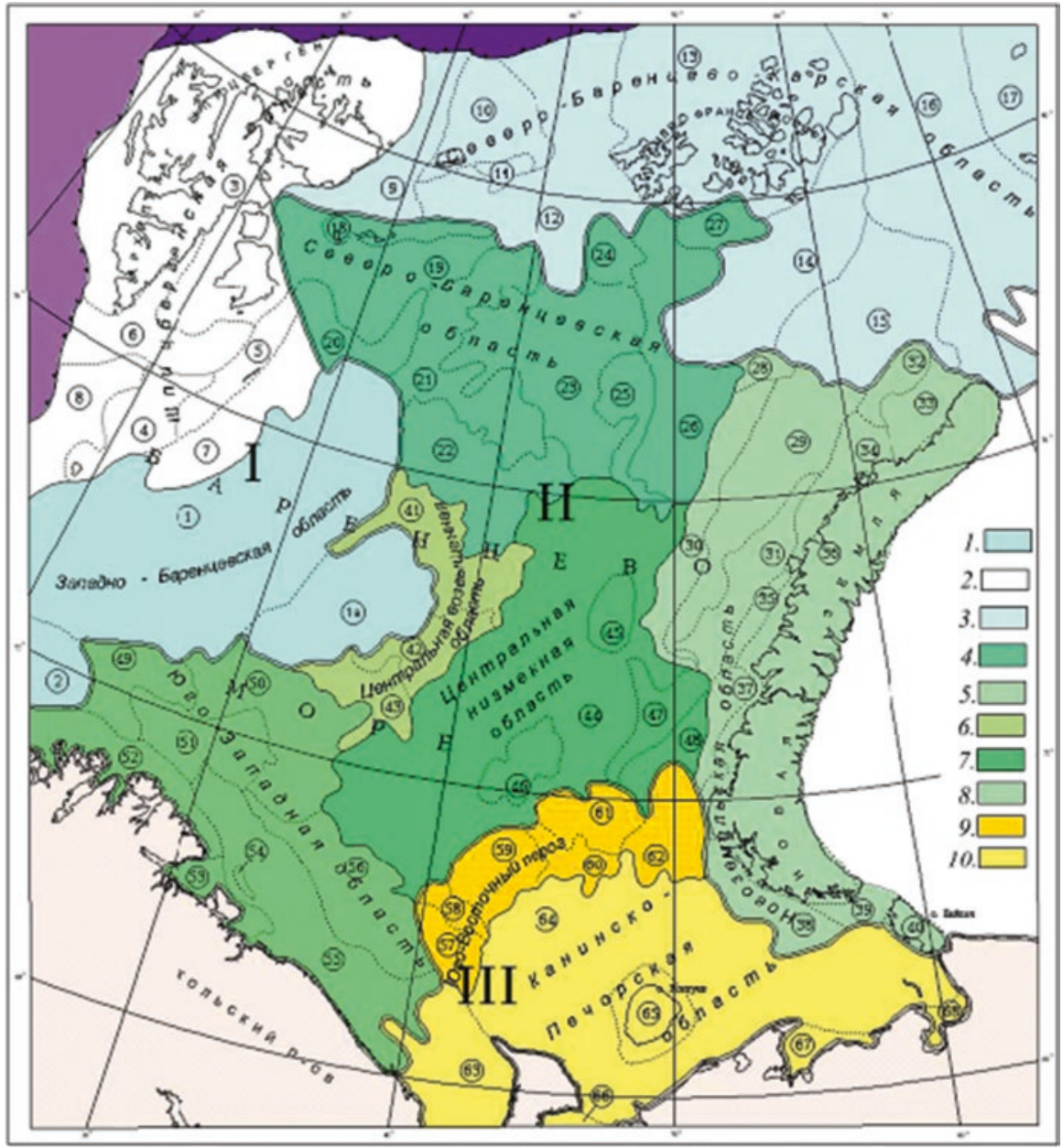

Fig. 4.7 Geomorphologic regionalization of the Barents Sea after Zinchenko (2000). I-III provinces, 1-10 areas, 1-68 local geomorphological elements of less scale. I Outer shelf province, areas: 1 West Barents Area of trenches and hollows (items 1-2), 2 Spitsbergen Upland Area (items: 3-8), 3 North Barents-Kara Area of elevations (items: 9-16). II: Inner shelf province, areas: 4 North Barents Plain Area (items: 17-27), 5 Novaya Zemlya Area of linear uplands and trenches (items: 28-40), 6 Central Upland Area (items: 41-43), 7 Central Lowland Area (items: 44-48), 8 South-Western Area mainly of linear uplands and trenches (items: 49-56). III: Shallow-water province, areas: 9 Kanin-Pechora's Area, South-Eastern Rapid (items: 57-62), 10 KaninPechora's Plain Area (items: 63-68)

6. Ecoregion of the Svalbard Archipelago and the in banks of Spitsbergen in Fig. 4.6 is located inside the Spitsbergen highland geomorphological area in Fig. 4.7 filled by Arctic water mass but influenced by the North Atlantic. It is characterized by high biodiversity. Trophic groups include macrophytobenthos, sessile and vagile sestonophagous-filtrators. On stony bottom grounds, the community of brown algae dominates. The community of sessile sestonophagous is formed 


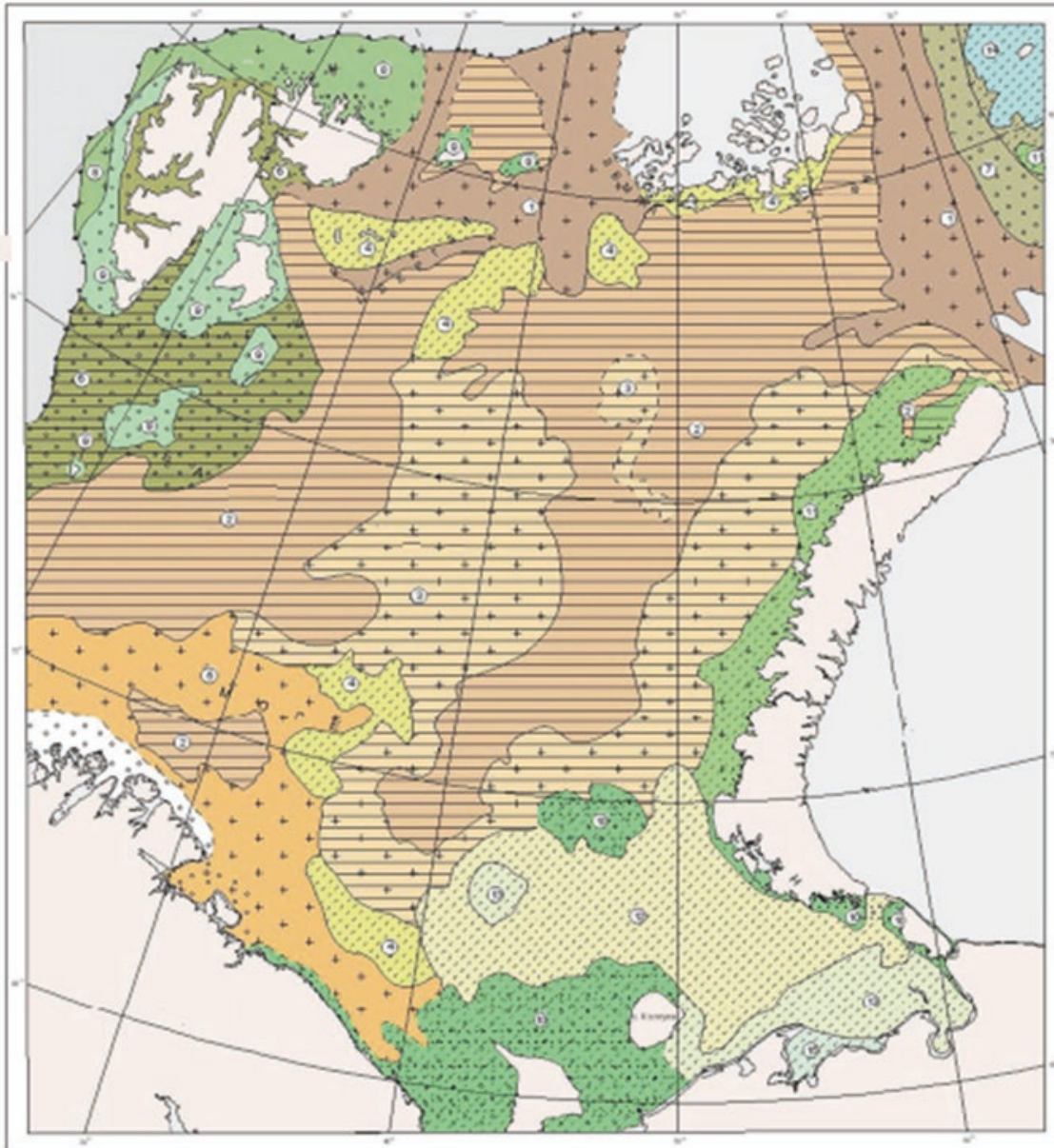

1.

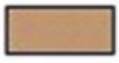

2.

3.

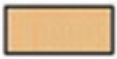

4.

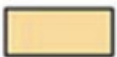

6.

7 .

8.
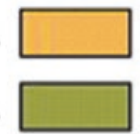

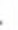

8.

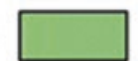

9.

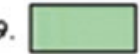

10.

11.

12.
13.

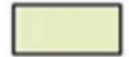

14.

15.

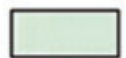

16.
17. $\because \because 3$

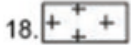

19.

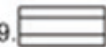

Fig. 4.8 Distribution of macrobenthos in the Barents Sea and adjacent waters (Kiyko et al. 2006). Communities: 1 Ophiopleura borealis + Hormosina globulifera, 2 Polychaeta + Sipunculoidea (Golfingia sp.), 3 Trochostoma sp., 4 Elliptica elliptica + Astarte crenata, 5 Brisaster fragilis, 6 soft bottom community adjacent to Svalbard, 7 community of Saint Anna trench slopes, 8 Strongylocentrotus sp. + Ophiopholis aculeata, 9 shoal community of sessile filter-feeders adjacent to Svalbard, 10 shoal community of sessile filter-feeders on Lithothamnion sp., 11 shoal community adjacent to western coast of Novaya Zemlya and Vise Island, 12 bivalve mollusc Tridonta borealis, 13 bivalve molluscs Ciliatocardium ciliatum + Macoma calcarea + Serripes groenlandicus, 14 bivalvie molluscs of Ushakov Plateau, 15 bivalve mollusc Macoma fusca; 16-19 regions of accumulation of pollutants: 16 chlorineorganics, $17 \mathrm{Fe}$ and $\mathrm{Mg}, 18$ polymetallics $\mathrm{Zn}, \mathrm{Sn}, \mathrm{Cu}$, $\mathrm{Ni}), 19$ all pollutants by ground feeders 
by Balanus balanus, Tridonta borealis, Hydroidea var., Nephthys sp. On soft grounds, Spiochaetopterus typicus, Nephthys sp., Lumbrinereis fragilis prevail.

7. Ecoregion of the Franz Josef Land Archipelago in Fig. 4.6 occupies the North Barents-Kara tectonic and geomorphological areas in Fig. 4.7 and is washed by the Arctic waters. Despite of its northern location, the coastal zone is characterized by both high biodiversity and productivity. The group of inhabitants includes acrophytobenthos, and sessile and vagile sestonophagous-filtrators. Among ground feeders are the communities of polychaeta and sipunculida, as well as the community of holothurian. The slope community of the Saint Anna trench is formed by Ascidiacea var., Nephasoma minuta, Thenea muricata.

\subsection{Conclusions}

In this article the current literature and knowledge on the hierarchical structure of large marine ecosystems was reviewed and based on that it was presented how the Russian Arctic shelf seas fit to the system. The emphasis has been done on the Barents Sea. The following conclusions based on experience of authors on biogeographical regionalization of sea basins including their rich theoretical (bibliographical) sources and own empirical material executed earlier issues, are summarized below.

1. The principles of the hierarchical zoning system of units were discussed by using the large marine ecosystem of the Barents Sea as an example.

2. Landscape-bionomic differentiation reflects three components of the oceanographic process: zonal, vertical and azonal., and three-rank system of units at regional level was introduced.

3. The formation of the marine basin bionomic structure is controlled by the oceanographic processes. In a multicomponent scheme of interactions the following functional links are distinguished: hydrological and geologo-geomorphological ones. Both of them cause a certain environmental pressure, effecting the structure and functions of the third link - the bionomic one.

4. The regionalization unit system is essential for monitoring, rational use and protection of marine biological resources at different hierarchical levels.

\section{References}

Barents Sea Ecoregion (2003) A biodiversity assessment. Proceedings of WWF biodiversity workshop. (http://assets.wwf.no/downloads/wwfrapport_barentsecoregionassessment_nov2003.pdf)

Bobkov AA, Petrov KM (2013) The Sea of Okhotsk as the large marine ecosystem. Part 1: methodology. In: Proceedings of the 28th international symposium on Okhotsk Sea \& Sea Ice (OSCORA). Mombetsu, Hokkaido, Japan, Feb 17-21, 2013, pp 324-327 
Kiyko OA, Kulakov MYu, Timofeyev SF, Chernova NV (2006) Ecosystem of the Barents and Kara seas coastal segment. The Global Coastal Ocean. Interdisciplinary Regional Studies and Syntheses. In: Robinson AR, Brink KH (eds) The sea: ideas and observation on progress in study of the seas. Vol. 14. Part B. Harvard University Press, Cambridge, MA, pp 1139-1176

Korotkevich ES (1985). Physico-geographical regionalization. Geohraphy of the World Ocean. North Polar and Southern oceans. In: Troshnikov AF, Sal'nikov SS (eds) Nauka, Leningrad, pp 120-129 (in Russian)

Petrov KM (2004) Bionomy of ocean. SPb.: SPb Press, 242 p (in Russian)

Petrov KM (2009) Large marine ecosystems: construction principles for a hierarchical system of arctic seas regionalization exampled with Barents Sea. J Biosphere 1(2):133-152. (in Russian)

Petrov KM (2012) Theory of hierarchical organization of large marine system. Palmarium Academic Publishing, Saarbrücken. 260 p. (in Russian)

Propp MW (1971) Ecology of coastal bottom communities of Murman Shore of Barents Sea. Nauka, Leningrad. 128 p. (in Russian)

Skern-Mautitzen M, Fall J (2010) Dolphin densities and distributions in the Barents Sea and potential influences by the recent temperature increase. 13 p. (http://www.iwcoffice.org/_documents/ sci_com/workshops/SmandCC/SC-N10-CC5.pdf)

Spalding MD, Fox HE, Allen GR, Nick Davidson N, Ferdana ZA, Finlayson M, Halpern BS, Jorge MA, Lombana A, Lourie SA, Martin KD, MCManus E, Molnar J, Recchia CA, Robertson J (2007) Marine ecoregions of the world: a bioregionalization of coastal and shelf areas. J Biosci. 57(2): 573-583. (http://www.biosciencemag.org)

Zenkevitch LA (1963) Biology of the seas of the USSR. Wiley-Interscience, New York. $955 \mathrm{p}$

Zinchenko AG (2000) Map of geomorphologic regionalization of Barents Sea. Atlas of Barents Sea. Funds of VNIIOkeangeologia, Saint-Petersburg. Computer variant of the map (in Russian)

Open Access This chapter is licensed under the terms of the Creative Commons Attribution 4.0 International License (http://creativecommons.org/licenses/by/4.0/), which permits use, sharing, adaptation, distribution and reproduction in any medium or format, as long as you give appropriate credit to the original author(s) and the source, provide a link to the Creative Commons license and indicate if changes were made.

The images or other third party material in this chapter are included in the chapter's Creative Commons license, unless indicated otherwise in a credit line to the material. If material is not included in the chapter's Creative Commons license and your intended use is not permitted by statutory regulation or exceeds the permitted use, you will need to obtain permission directly from the copyright holder.

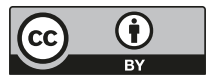

